\title{
Immunological and antimicrobial molecules in human tears: a review and preliminary report*
}

\author{
R Schnetler ${ }^{\mathrm{a}}$, WDH Gillan ${ }^{\mathrm{b}}$ and G Koorsen ${ }^{\mathrm{a}}$ *
}

Department of Biochemistry ${ }^{a}$ and Department of Optometry ${ }^{b}$, University of Johannesburg, PO Box 524, Auckland Park, 2006 South Africa

<gkoorsen@uj.ac.za>

Received 1 March 2012; revised version accepted 31 August 2012

\begin{abstract}
The human tear film is a multi-layered and chemically complex structure, which performs numerous functions relating to the health of the corneal surface. One of the core functions of the tear film is to protect the eye against invasion by pathogens. Thus its middle layer, the "core aqueous stratum', harbours a myriad of immunological and antimicrobial proteins. In this review we discuss the most abundant of these proteins (immunoglobulins, toll-like receptors, cytokines, lactoferrin, lysozyme, lipocalins, surfactant protein-A and -D and defensins). In order to illustrate how the levels of immunological/antimicrobial proteins in tears change in response to eye disease, we re-
\end{abstract}

view literature in which levels of these proteins have been measured in tears of patients with dry eye disease (DED) and keratoconus (KC). Finally, we report results of a preliminary study to measure the concentration of secretory immunoglobulin A $(\operatorname{sig} \mathrm{A})$ in the tears of DED and $\mathrm{KC}$ patients. The study showed a significant decrease of sIgA levels in DED compared to control. Further analysis must be done to determine whether or not DED and KC may be associated with differential expression of immune proteins. (S Afr Optom 2012 71(3) 123132)

Key words: tear proteins, immunological proteins, dry eye disease, keratoconus, antimicrobial proteins.

\section{Introduction}

The surface of the human eye is covered by a tear film (TF), also known as the precorneal tear film $(\mathrm{PTF})^{1}$ or commonly known as tear fluid ${ }^{2}$. Tear fluid is a complex liquid produced by various glands associated with the human eye. These gland secretions are transported by means of ducts that open on the ocular surface ${ }^{2}$. Traditionally, the PTF has been thought to consist of three discrete layers. This three-layered structure (first presented by $\mathrm{Wolff}^{3}$ ) has an outer li- pid layer produced by the meibomian glands within the tarsal plate of the upper and lower eyelids; the core aqueous stratum which consists of various proteins, electrolytes and water produced by the lacrimal glands and accessory lacrimal glands and lastly the inner mucous or mucin layer covering the corneal and conjunctival epithelium 3,4 . The corneal and conjunctival epithelia synthesize a mucin-like glycoprotein $\left(\mathrm{MUC}^{1}\right)$ at the apical surface of the epithelium to constitute the glycocalyx ${ }^{5}$, see Figure 1.

*This article results from research towards a MSc (Biochemistry) degree in the Department of Biochemistry at the University of Johannesburg under the supervision of Dr G Koorsen and co- supervision of Prof WDH Gillan 


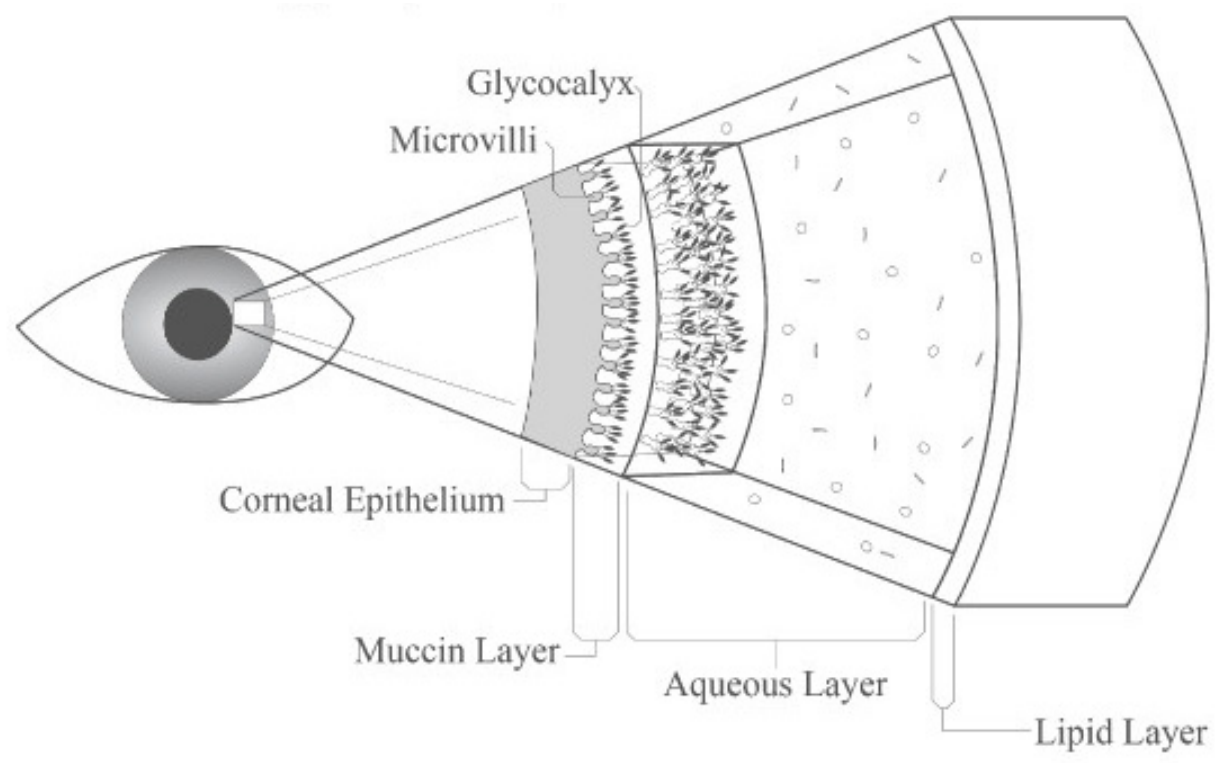

Figure 1 Schematic illustration of the precorneal tear film showing the corneal epithelium with its glycocalyx, mucin, aqueous and lipid layers.

In 1973 a concept of the PTF was proposed by Hol$1 y^{6}$. This modern concept was then later refined by McCulley and Shine ${ }^{7}$ who concluded that the tear film lipid layer is composed of two phases: the one being a thin polar phase adjacent to the aqueous-mucin phase and the second being a thick nonpolar phase associated with both the polar phase and the air interface. Butovich ${ }^{8}$ reviewed this refined model and stated that this model did not take into account proteins inserting into the lipid layer nor the size of an outer lipid layer that may be up to 20 molecules thick.

Another concept of the PTF, proposed by Lemp ${ }^{9}$ is that of a metastable tear film composed of an aqueous gel with a gradient of mucin content decreasing from the ocular surface to the surface of the outer most lipid layer. This proposed structure is said to interact with the underlying aqueous and mucin components 9 . Below we discuss the functions of the TF. However, the purpose of this paper is to discuss the immunological and antimicrobial molecules present in tear fluid.

\section{Functions of the PTF}

Each of the three layers plays important biochemical roles. For the purpose of this article only the chief functions of each layer will be highlighted. Firstly, the PTF outer lipid layer, which is a hydrophobic barrier ${ }^{10}$, provides an optically smooth surface for the cornea ${ }^{11}$ that helps to prevent the evaporation of the aqueous phase of the TF and forms a water-tight seal for closed eyelids during sleep ${ }^{10}, 12$. Inadequate amounts of meibomian oil secretion may result in the PTF becoming unstable; this is thought to be one of many causes of dry eye disease ${ }^{13}$.

The core aqueous stratum (middle layer) is quantitatively the most important and it functions in generating the appropriate environment for the epithelial cells of the ocular surface, carrying essential nutrients and oxygen to the cornea, allowing cell movement over the ocular surface, as well as washing away epithelial debris, toxic elements and foreign bodies ${ }^{14}$. This layer contains many of the defensive proteins and antibodies. The composition of the aqueous layer changes rapidly in response to environmental or bodily conditions and can influence the health, proliferation, maturation and movement of the surface epithelial cells ${ }^{5}$. The protein composition of this remarkable layer is commonly studied to find possible indicators of various ocular diseases ${ }^{14}$. This aqueous layer is home to the myriad of immunological molecules that are the focus of this review.

Lastly, the function of the inner mucin layer is to ensure that the TF covers the entire ocular surface and also to ensure firmness of the aqueous layer over the ocular surface ${ }^{14}$ and it is important for proper ocular surface wetting 5 . This inner mucin layer prevents adhesion of foreign debris, cells or pathogens to the ocular surface. Mucins MUC-4 and MUC-5AC are also produced by the conjunctiva and may play a role in forming the tear-film layer at the air and ocular surface-epithelium interface 5 . 
The mechanism of the blink is not yet fully understood, but it plays a role in maintaining corneal integrity by spreading the $\mathrm{TF}^{15}$. Immediately after the blink, the TF starts to thin in an orderly fashion, maintaining a complete or continuous aqueous cover until the next blink occurs, re-establishing a thicker film and so the process repeats itself ${ }^{4}$.

\section{The immunological and antimicrobial composi- tion of human tears}

One may question whether the composition of tears can be useful for diagnostic purposes of various ocular disorders, but from a biochemical point of view, the more important question is how the composition of tears changes in response to a specific disease ${ }^{16}$. Lately, biochemical analysis of the composition of the tear fluid has been utilized to detect a variety of diseases and has also been useful in understanding disease etiology. Comprehensive studies have been done on the composition of tear fluid to date ${ }^{11}$. Tears are generally composed of proteins and smaller peptides, metabolites, electrolytes, carbohydrates, a tremendously complex combination of lipids and other low- and high molecular weight compounds ${ }^{8,14}$.

The lacrimal gland secretes numerous amounts of proteins which act as antimicrobial factors or have an immunological function giving tear fluid the ability to be bacteriostatic as well as bacteriolytic. Some of these factors include lactoferrin (LF), lysozyme, tolllike receptors (TLR), secretory immunoglobulin A (sIgA), complement proteins, mucin glycoproteins, surfactant protein-A and D (SP-A and SP-D), and defensin antimicrobial peptides ${ }^{4,17}$.

The immunological and antimicrobial molecules play an important role in maintaining ocular health by protecting the eye from various pathogens and other foreign particles that the eye is generally exposed to ${ }^{18}$. The immune system operating at the ocular surface involves both an innate and an adaptive immunity ${ }^{4}$.

\section{Innate and adaptive immunity}

The innate immune system is also referred to as the non-specific immune system and can be seen as a first-line immune reaction to an unexpected pathogen. The activation of innate immunity leads to the activation of the adaptive immune system. An innate response to an infection is an immediate, nonspecific reaction, which is mediated by mast cells, neutrophils, monocytes, macrophages, natural killer cells and Tcells and B-cells. Upon reaction to pathogens, various mediators are expressed to produce a cascading reaction, for example mast cells produce Tumor Necrosis Factor (TNF- $\alpha$ ), Interleukin (IL)-1, IL-3, IL-4, IL-6, Granulocyte Macrophage Colony Stimulating Factor (GM-CSF) and histamine, which have multiple effects on T-, B- and other immune cells and receptors in the nervous and endocrine systems ${ }^{19}$.

Adaptive (otherwise known as acquired) immunity is mediated by B- and T-cells or a combination of both. The adaptive immune system is divided into two classes: humoral and cell-mediated immunity. In cellmediated immunity T-cells are activated by the exposure of an antigen $(\mathrm{Ag})$ to $\mathrm{Ag}$ presenting cells such as monocytes, macrophages and B-cells. The T-cells can form complexes with other cells carrying the same $\mathrm{Ag}$ (virus-infected cells) and then initiate neutralisation of it. B-cells, which activate humoral immunity, present immune proteins on their surface known as immunoglobulins ( $\mathrm{Ig}$ ) or more commonly referred to as antibodies $(\mathrm{Ab})$. The antibodies on the B-cells only recognise specific antigens. Upon the recognition of antigens, the B-cells are activated by the Ig receptor: Ag complex ${ }^{20,21}$. The activation causes the B-cells to develop into plasma cells which secrete their antibodies into the blood or lymph. The B-cells can also divide and differentiate into memory so that the body can be protected from that specific pathogen when it is presented again ${ }^{21}$.

There are five different classes of circulating antibodies: IgG, IgM, IgA, IgD and IgE. The basic unit of an $\mathrm{Ab}$ is a monomer, which is a Y-shaped structure that contains four subunits. These subunits, two identical light chains and two identical heavy chains, are associated with each other by disulfide bonds via non-covalent interactions. These Y-shaped monomers can become chemically bonded with other Y-shaped monomers to form polymeric antibodies. An example is $\operatorname{IgA}$, which occurs as a monomer, dimer or trimer ${ }^{22}$.

\section{Immunological and antimicrobial proteins \\ IgA antibodies (adaptive)}

The lacrimal gland contains a diverse array of lymphocytes, including plasma cells, T-cells, B-cells, dendritic cells and macrophages as well as a high concentration of IgA and IgD plasma cells ${ }^{23}$. IgApositive plasma cells account for the majority of the 
mononuclear cells in the lacrimal gland ${ }^{24-26}$. Secretory $\operatorname{IgA}(\operatorname{sg} \mathrm{A})$ in tears serve as the primary mediators of specific immunity in the TF, which is apparently important during prolonged eye closure ${ }^{23}$. Tears contain less polymeric IgA, monomeric $\operatorname{IgA}$, IgG, $\operatorname{IgM}$ and $\operatorname{IgE}$ than $\operatorname{sg} \mathrm{A}$. The concentration of various antibodies in tears may rise dramatically during infection. An increase in IgA, IgG and IgM levels can be an indication of acute adenoviral conjunctivitis, acute bacterial conjunctivitis, acute follicular conjunctivitis, chronic KC27 et cetera. An increase in IgE levels in tears can be an indication of allergic conjunctivitis, atopic conjunctivitis, giant papillary conjunctivitis and vernal keratoconjunctivitis ${ }^{23,28}$.

\section{Toll-like receptors (innate and adaptive)}

The innate and adaptive immune systems are activated upon recognition of specific pathogen associated molecular patterns (PAMPs) which are specific molecules that have remained conserved through related taxa and similar species throughout evolution; they are therefore evolutionary conserved. PAMPs are evolutionary conserved (their genes have remained unchanged through evolution) pathogen-derived molecules, which have the capability to activate the innate and adaptive immune systems. Examples of PAMPs include flagellin, peptidoglycan, lipoteichoic acid and lipopolysaccharide ${ }^{29}$. PAMPs are recognised by a family of TLR proteins on corneal epithelial cells. To date ten functional human TLRs have been identified, ${ }^{30}$ each with their own unique function.

TLRs play an important role in the ocular surface immune response to pathogens. TLR activation activates the innate immune system by means of the production of cytokines and chemokines. Cytokines and chemokines are both important molecules for the stimulation of immune and inflammatory cell infiltration into the area of the pathogenic attack to resolve infection. The TLRs can also activate the acquired immune system by increasing the expression of major histocompatibility complex class II and co-stimulatory molecules in the cornea and conjunctiva ${ }^{30-32}$. The immune system might prevent the pathogens from causing ocular damage but the number of inflammatory molecules released can damage the ocular surface $^{30}$. TLRs are involved in various ocular surface disorders such as Herpes simplex keratitis (TLR2, 3, 4, 7, 9); Pseudomonas keratitis (TLR4, 5, 9), Sjögren's syndrome dry eye (TLR1, 2, 3, 4) and Non-Sjögren's syndrome dry eye (TLR2, 4, 5, 9). For more details on TLRs and their roles in ocular surface disease, the reader is referred to a recent review by Redfern and McDermott ${ }^{30}$

\section{Cytokines (innate and adaptive)}

Researchers in ocular immunology have turned their attention to the cytokine content of tears and its inferences in the processes of ocular inflammation ${ }^{33}$. Cytokine is a general term for any kind of communication molecule. These molecules are secreted in low amounts and act locally at the site of release in reaction to illness, injury or inflammation. One of their functions is to serve as a signal transmitter or messenger between cells to control an immune response ${ }^{34}$.

The pro-inflammatory cytokine IL-1 is an important mediator of inflammation, immunity and wound healing 35,36 . Typical causes of ocular inflammation include the impairment of any of the physiological processes that protect the eye such as infrequent lubrication facilitated by blinking, lowered tear production and the lack of antimicrobial substances in tears ${ }^{37}$. IL-1 comprises two pro-inflammatory forms (IL- $1 \alpha$ and IL-1 $\beta$ ) and one naturally occurring anti-inflammatory form, IL-1 Receptor Antagonist ${ }^{38}$. IL- $1 \beta$ regulates the secretion of inflammatory cytokines such as IL-6, IL-8, TNF and GM-CSF by human corneal epithelial cells (HCEC) in the event of a microbial confrontation ${ }^{35-36}$. Although IL-1 plays a significant role in inflammation and wound healing, increased levels of it at the ocular surface are said to contribute to the epithelial damage observed in patients with aqueous deficient or evaporative dry eye ${ }^{35}$.

In healthy tears, pro-inflammatory cytokines that have been measured include: IL-1 $\alpha$, IL-1 $\beta$, IL-6, IL-8, Transforming Growth Factor (TGFb-1) as well as Vascular Endothelial Growth Factor (VEGF) ${ }^{33}$. These inflammatory mediators function to attract and retain inflammatory cells in the conjunctiva ${ }^{39}$. Comparison of the levels of cytokines within the lacrimal fluid of healthy and diseased patients can increase our knowledge of the pathology of certain ocular diseases. Previous studies have reported elevated levels of the cytokines described above as well as the presence of TNF- $\alpha$, IL-4, IL-5, Interferon, GM-CSF and eotaxin in the tears associated with various ocular diseases such as keratoconjunctivitis sicca, Sjögren's 
Syndrome, Non- Sjögren keratoconjunctivitis sicca, Seasonal Allergic Conjunctivitis and Atopic Keratoconjunctivitis 33,35 .

\section{Lactoferrin (innate and antimicrobial proteins)}

In the PTF, LF is a non-haem iron-binding protein that is part of the transferrin protein family ${ }^{40}$ and is produced in the acinar cells of the lacrimal gland ${ }^{18}$. LF was first reported in human tears by Masson et $a l^{40}$ This protein has various functions which include immune response, antibacterial, antioxidant, anticarcinogenic and anti-inflammatory properties ${ }^{12,18}$. The antimicrobial activity of LF is based on two mechanisms. The first mechanism causes a bacteriostatic effect by blocking iron in the area of infection, thus preventing the microorganism from using the iron as a nutrient. The second mechanism causes cell lysis on bacterial, viral, fungal and parasite surfaces. This mechanism is achieved by positively charged amino acids in LF that interacts directly with the anionic molecules on the surfaces of these infectious agents, thus breaking the cell ${ }^{41}$.

Although LF plays a role in the anti-inflammatory and immunomodulatory process, the mechanism is not well established ${ }^{18}$. The concentration of LF in the tears of a healthy person is about $2.2 \mathrm{mg} / \mathrm{ml}^{18}$ whereas in a person with SS the concentration is half of that ${ }^{42}$. The levels of LF are lower in SS due to the fact that one of the causes of SS is an autoimmune disease of the lacrimal gland. Thus LF cannot be secreted by the lacrimal glands. A few more examples of decreased LF levels are in other diseases like idiopathic dry eye, myotonic muscular dystrophy, $\mathrm{KC}^{43}$, et cetera.

\section{Lysozyme (Innate and antimicrobial proteins)}

Lysozyme is the most alkaline protein in tears and makes up $20-40 \%$ of total tear proteins ${ }^{44,} 45$. Lysosomes secrete higher levels of this enzyme in the PTF than in any other body fluid ${ }^{45}$. The lysosomes that secrete lysozyme in the tear fluid are situated within the lacrimal glands ${ }^{46}$. Lysozyme plays a role in innate immunity against bacteria and is thus also called an antibacterial enzyme ${ }^{47}$. The role of lysozyme in innate immunity is to break down the peptidoglycan within bacterial cell walls thus destroying bacteria. Gram positive bacteria invading the ocular surface are most likely to be destroyed by lysozyme ${ }^{41}$. It has been reported that lysozyme levels decrease with age and in patients with $\mathrm{SS}^{45}$. Lysozyme has been shown to increase in patients with $\mathrm{KC}^{48}$.

\section{Lipocalin (Innate and antimicrobial proteins)}

Lipocalin is a multi-functional protein produced mainly by the lacrimal glands but it is also expressed by the glands of Von Ebner (salivary glands) and possibly by the meibomian glands of the eyelid as well. Lipocalin is said to be packaged into granules accompanied by lysozyme and lactoferrin and secreted from the lacrimal gland into the tear fluid. Gasymov et al showed that tear lipocalin interacts with both lysozyme and lactoferrin and suggested that these three molecules might function in concert ${ }^{49}$. Tear lipocalin plays various roles in maintaining the health of the ocular surface. For example, it maintains viscosity and a low surface tension in the tear film, thus maintaining the stability of the tear film ${ }^{45,50}$. A shortage of lipocalin is said to cause a precipitation of the tear film, which results in the formation of mucous strands and then finally a disorder of the stability of the $\mathrm{TF}^{51}$.

\section{Surfactant protein- $A$ and $-D$ (Innate and antimicro- bial proteins)}

Surfactant protein A and D (SP-A and SP-D) are members of the collectin family. They protect the ocular surface via the innate immune response ${ }^{52}$. SP-A and SP-D bind to the surfaces of various microbes leading to a variety of well-characterized anti-microbial functions including aggregation and neutralization, opsonisation for phagocytosis, direct gram-negative bacteria cell-membrane lysis and also inhibition of bacterial and fungal growth in macrophages ${ }^{53}$.

\section{Defensins (Innate and antimicrobial proteins)}

Narayanan et al $^{54}$ proposed that naturally occurring $\beta$-defensins (hBDs), which are antimicrobial peptides involved in the innate host defence system, act as an alternative means of defence for compromised ocular surfaces. There are two types of defensin families, $\alpha$ and $\beta$, which occur in the human body. Defensins are believed to have antimicrobial effects by forming pores in the membranes of various bacteria (especially gram negative bacteria) and fungi as well as enveloped viruses ${ }^{17,54}$. Recent in vivo studies in animal models have shown that cathelicidin and defensins play an important role in protecting the ocular surface 
from Pseudomonas aeruginosa (PA) infection ${ }^{55}$.

How do levels of immunological molecules differ in tears of patients with different ocular diseases?

In order to illustrate how immunoprotein levels differ in distinct ocular diseases we have extensively re- viewed the literature on $\mathrm{KC}$ and DED. A summary of the difference in immunoprotein levels in DED and $\mathrm{KC}$ compared to healthy subjects is given in Table 1. Up arrows indicate an increase in protein levels compared to control, whereas down arrows indicate a decrease. Horizontal arrows indicate no difference.

Table 1 Overview of the relative levels of immunoproteins in the tears of patients with dry eye disease and keratokonus. $\leftrightarrow$ No change in protein level compared to coltrol; $\uparrow$ Increase in protein level compared to control; $\downarrow$ Decrease in level compared to control; *Proteins of which the levels differ in KC and DED; AQP5, Aquaporin 5; CXCL, Chemokine (C-X-C motif) ligand; CXCR, Chemokine receptor; EGF, Epidermal growth factor; ICAM, Intercellular adhesion molecule; IFN, Interferon; IgG, Immunoglobulin G; IGKC, Immunoglobulin kappa chain; IgM, Immunoglobulin M; IL, Interleukin; MIP, Macrophage inflammatory protein; MMP, Metalloproteinase; PIP, Prolactin-inducible protein; S100, calgranulin; S100 A11, calgizzarin; sIgA, Secretory immunoglobulin A; TIMP, Tissue inhibitor of metalloprotease; TNF- $\alpha$, Tumour necrosis factor alpha; TRAIL-R1, Tumor necrosis-related apoptosisinducing ligand-R1; VCAM, Vascular adhesion molecule; VEGF, Vascular endothelial growth factor; ZAG, Zinc- $\alpha 2$-glycoprotein.

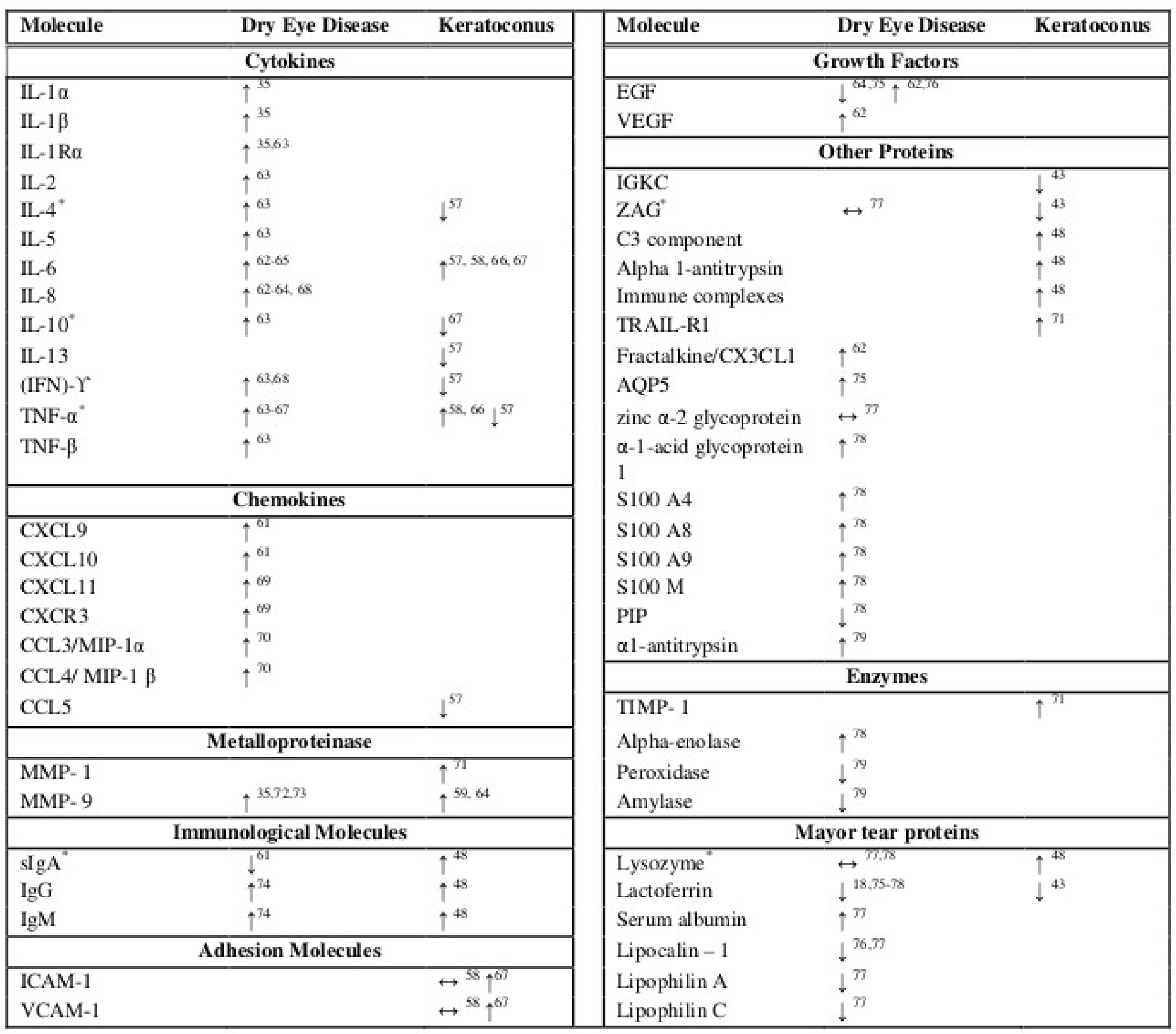


Clearly, there are gaps in the literature regarding the levels of immunoproteins in these diseases. For example, the level of many ILs is yet to be determined in the tears of $\mathrm{KC}$ patients. Furthermore, there are conflicting reports on the levels of TNF- $\alpha$ for example, which has been reported to be elevated in $\mathrm{KC}$ compared to healthy tears by some ${ }^{56,57}$ and to be lower in $\mathrm{KC}$ by others ${ }^{58}$. Epidermal Growth Factor (EGF) levels in DED are also disputed (see Table 1). It is interesting to note that the levels of certain proteins (indicated by an asterisk in Table 1) are elevated in one disease state but lower in another. sIgA concentrations, for example, are lower in DED but higher in $\mathrm{KC}$ compared to healthy subjects.

\section{Preliminary investigation}

To address some of these issues, we have commenced a study in which we are evaluating the levels of immunological proteins in subjects with symptoms of DED and $\mathrm{KC}$ compared with healthy (control) subjects. Amongst other proteins, we evaluated sIgA, a predominant tear immunoglobulin. sIgA, together with active phagocytes and lysozyme, plays a defensive role against various pathogens by providing a first line of defense to protect the ocular surface ${ }^{59}$. The concentration of SIgA is compromised by an increased tear flow rate. Thus in tears of healthy humans the sIgA concentration in unstimulated (basal) tears is $\sim 100-900 \mu \mathrm{g} / \mathrm{ml}$ and in stimulated (reflex) tears $\sim 200$ $\mu \mathrm{g} / \mathrm{ml} .^{60}$

In our study (ongoing), tears were collected with $10 \mu \mathrm{l}$ glass micro-capillary tubes and care was taken not to touch the globe to prevent reflex tearing. Patients for this study included three groups: Control $(n=10)$, DED $(n=10)$ and $\mathrm{KC}(n=6)$. For the control group, the volunteers were all non-contact lens wearers who had been free from ocular infection for at least three years. Each individual in this group was examined to be sure that they do not have DED or $\mathrm{KC}$. KC volunteers were examined by slit lamp biomicroscopy to confirm signs of KC. DED volunteers were selected based on a verified dry eye disease questionnaire. A ELISA (Enzyme-Linked Immunosorbent Assay) kit (DRG® Secretory IgA EIA-4601) was used for this study. ELISA is a highly sensitive method used to determine if a particular protein is present in a specific sample and can also quantify the amount of protein present. Preliminary results of our study are presented in Figure 2. A standard curve was constructed using known concentrations of sIgA (0$600 \mu \mathrm{g} / \mathrm{ml}$ ) and absorbance was measured at a wavelength of $405 \mathrm{~nm}$ (Figure 2a). The tear samples from the different groups fell well within the sensitivity range of the ELISA kit.
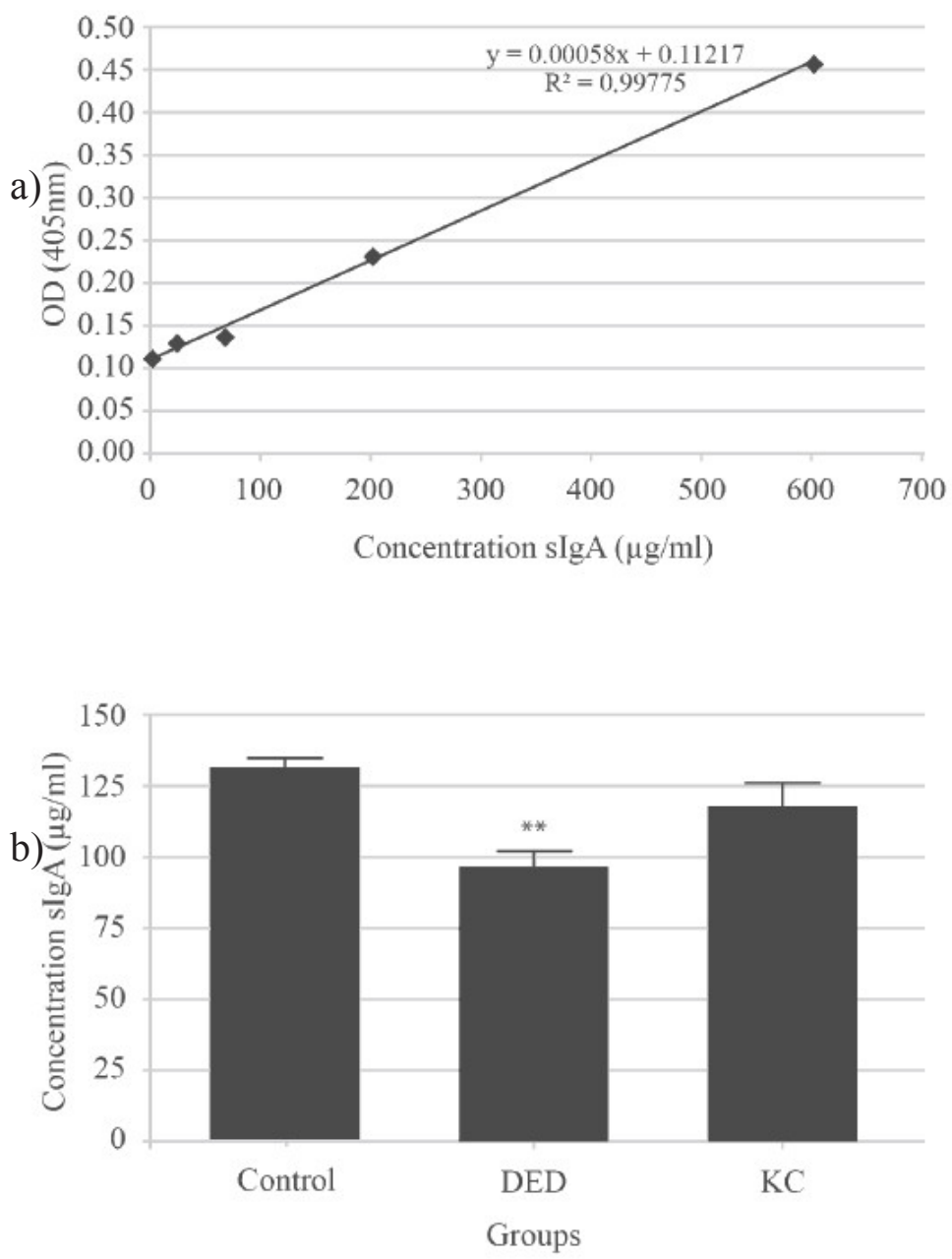

Figure 2 Tear sIgA levels in control, DED and $\mathrm{KC}$ patients. a.) Calibration curve used to determine unknown sample concentrations from absorbance measurements of protein standards at $405 \mathrm{~nm}$. b.) Comparison of tear sIgA concentrations from control $(n=10)$, dry eye disease (DED; $n=10)$ and keratoconus $(\mathrm{KC} ; n=6)$ patients. Statistical analyses were performed with commercial software (GraphPad Prism 5). Analyses performed include ANOVA and unpaired $t$-test. $* *=P<0.001$.

\section{Discussion and conclusion}

We found that levels of SIgA in patients with DED were significantly lower compared to controls whereas there was no difference between sIgA levels in $\mathrm{KC}$ patients and controls (Figure 2b). Our findings are consistent with a report by Hoshino et al ${ }^{61}$ who found a significant difference in the sIgA levels between subjects with DED $(n=13 ; P<0.001)$ and a 
control group $(n=29)$. However, our measurements of sIgA levels for $\mathrm{KC}(n=6)$ differ from a previous report: Gorskova et al ${ }^{48}$ reported that sIgA levels are higher in $\mathrm{KC}$ compared to control subjects whereas we found no significant difference in this study. Our ongoing study has a statistical advantage over previous studies, since we are examining a greater number of tear samples. However, a complete picture of the immune functions of the tear film will only emerge after studying all the different immune proteins present in the PTF.

\section{Further work}

Further analysis must be done to determine whether or not DED and KC may be associated with differential expression of immune proteins. Studies are also needed to conclude if there is any fundamental association or correlation between the etiology of these conditions and the immunoprotein fingerprint in tears. To address some of these issues, we are continuing to perform ELISA measurements to measure immunoproteins like metalloproteinase 1 (MMP-1) and TNF- $\alpha$.

\section{Acknowledgment}

The study was supported by the University of Johannesburg and the National Research Foundation (via an Innovation Scholarship to RS). The authors would like to thank volunteers from the University of Johannesburg and Michael J Van Niekerk for his help in the tear film illustration.

\section{References}

1. Wolkoff P. Ocular discomfort by environmental and personal risk factors altering the precorneal tear film. Toxicol Lett 2010199 203-212.

2. Dartt DA. Regulation of mucin and fluid secretion by conjunctival epithelial cells. Prog Retin Eye Res 200221 555576.

3. Wolff E. The muco-cutaneous junction of the lid margin and the distribution of the tear fluid. Trans Ophthalmol Soc UK 194666 291-308.

4. Lemp MA. Advances in understanding and managing dry eye disease. Am J Ophthalmol 2008146 350-356.

5. Rolando MMD, Zierhut MMD. The ocular surface and tear film and their dysfunction in dry eye disease. Surv Ophthalmol 200145 203-210.

6. Holly FJ. Formation and rupture of the tear film. Exp Eye Res 197315 515-525.
7. McCulley JP, Shine W. A compositional based model for the tear film lipid layer. Trans Am Ophthalmol Soc 1997 45 79-93.

8. Butovich IA. On the lipid composition of human meibum and tears: comparative analysis of nonpolar lipids. Invest Ophthalmol Vis Sci 200849 3779-3789.

9. Lemp MA. Report of the national eye institute/industry workshop on clinical trials in dry eyes. CLAO J 199521 221-32.

10. Nicolides N, Kaitaranta JK, Rawdah TN, Macy JI, Boswell FM, Smith RE. Meibomian gland studies: comparison of steer and human lipid. Invest Ophthalmol Vis Sci 198120 522-536.

11. Bron AJ, Tiffany JM, Gouveia SM, Yokoi N, Voon LW. Functional aspects of the tear film lipid layer. Exp Eye Res 200478 347-60.

12. Goto E, Endo K, Suzuki A, Fujikura Y, Matsumoto Y, Tsubota K. Tear evaporation dynamics in normal subjects and subjects with obstructive meibomian gland dysfunction. Invest Ophthalmol Vis Sci 200344 533-539.

13. Ong BL, Larke, JR. Meibomian glands dysfunction: some clinical, biochemical and physical observations. Ophthal Physiol Opt 199010 144-148.

14. Filik J, Stone N. Analysis of human tear fluid by Raman spectroscopy. Analytica Chimica Acta 2008616 177-184.

15. Al-Abdulmunem M. Relation between tear breakup time and spontaneous blink rate. ICLC 199926 117-120.

16. Tiffany JM. Tears in health and disease. Eye 200317923 926.

17. Maltseva IA, Fleiszig SMJ, Evans DJ, Kerr S, Sidhu SS, McNamara NA, Basbaum C. Exposure of human corneal epithelial cells to contact lenses in vitro suppresses the upregulation of human b-defensin-2 in response to antigens of Pseudomonas aeruginosa. Exp Eye Res 200785 142153.

18. Flanagan JL, Willcox MDP. Role of lactoferrin in the tear film. Biochimie 200991 35-43.

19. Hook GER, Lucier GW. Reviews in Environmental Health: Toxicological Defense Mechanics. North Carolina: Diane Publishing, 199888.

20. Chervin AS. The Role of T Cell Receptor: Peptide MHC Affinity in T Cell Activation. New Jersey: Proquest, 2009, pp4-5.

21. Welsh DM. Alcohol's Effect on Organ Function. Springfield: Diane Publishing, 199733.

22. Voet D, Voet JG, Pratt CW. Fundamentals of Biochemistry: Life at the Molecular level. New Jersey: John Wiley \& Sons, 2006.

23. Zierhut M, Dana MR, Stern ME, Sullivan DA. Immunology of the lacrimal gland and ocular tear film, Trends Immunol 200223 333-335.

24. Zoukhri D. Effect of inflammation on lacrimal gland function. Exp Eye Res 200682 885-898.

25. Dua HS, Gomes JA, Jindal VK, Appa SN, Schwarting R, Eagle Jr, RC, Donoso LA, Laibson PR. Mucosa specific lymphocytes in the human conjunctiva, corneoscleral limbus and lacrimal gland. Curr Eye Res 199413 87-93. 
26. Wieczorek R, Jakobiec FA, Sacks EH, Knowles DM. The immunoarchitecture of the normal human lacrimal gland, relevancy for understanding pathologic conditions. Ophthalmol 198895 100-109.

27. Gorskova EN, Tarasova LN, Teplova SN, Sevost'ianov EN, Alekhina TV. State of local immunity in keratoconus. Vestn Oftalmol 1998114 26-28.

28. Pleyer U, Zierhut M, Behrens-Baumann W. Immuno-ophthalmology. Basel: Karger Publishers, 199956.

29. Kumar A, Zhang J, Yu FX. Toll-like receptor 2-mediated expression of b-defensin-2 in human corneal epithelial cells. Microb Infect 20058 380-389.

30. Redfern RL, McDermott AM. Toll-like receptors in ocular surface disease. Exp Eye Res 2010906 679-687.

31. Hamrah P, Dana MR. Corneal-antigen presenting cells. Chem Immunol Allergy 200792 58-70.

32. Yamagami S, Yokoo S, Amano S, Ebihara N. Characterisation of bone marrow derived cells in the substantia propria of the human conjunctiva. Invest Ophthalmol Vis Sci 2007 48 4476-4481.

33. Cook EB, Stahl JL, Lowe L, Chen R, Morgan E, Wilson J, Varro R, Chan A, Graziano FM, Barney NP. Simultaneous measurement of six cytokines in a single sample of human tears using microparticle-based flow cytometry: allergics vs. non-allergics. J Immunol Methods 2001254 109-1180.

34. United States Congress, Office of Technology Assessment. Identifying And Controlling Immunotoxic SubstancesBackground paper. Washington DC: USA Government Printing Office, 1991334.

35. Solomon A, Dursun D, Liu Z, Xie Y, Macri A, Pflugfelder SC. Pro- and anti-inflammatory forms of interleukin-1 in the tear fluid and conjunctiva of patients with dry-eye disease. Invest Ophthalmol Vis Sci 200142 2283-2292.

36. Narayanan S, Glasser A, Hu Y, McDermott AM. The effect of interleukin-1 on cytokine gene expression by human corneal epithelial cells, Exp Eye Res 200580 175-183.

37. Elliott D, Aitken L, Chaboyer W. ACCCN's Critical Care Nursing. Chatswood, NSW: Elsevier, 2007, 108.

38. Dinarello CA. Interleukin-1. In: Thomson, A. ed. The Cytokine Handbook. Boston: Academic Press, 1998 p315.

Luo L, Li DQ, Doshi A, Farley W, Corrales RM, Pflugfelder

39. SC. Experimental dry eye stimulates production of inflammatory cytokines and MMP-9 and activates MAPK signaling pathways on the ocular surface. Invest Ophthalmol Vis Sci 200445 4293-4301.

40. Masson PL, Heremans JF, Dive C. Studies of the proteins of secretions from two villous tumours of the rectum. Gastroenterologia 1966105 270-282.

41. Gonzalez-Chavez SA, Arevalo-Gallegos S, Rascon-Cruz Q. Lactoferrin: structure, function and applications, Int $J$ Antimicrob Agents 200933 301-308.

42. Fujihara T, Nagano T, Nakamura M, Shirasawa E. Lactoferrin suppresses loss of corneal epithelial integrity in a rabbit short-term dry eye model. J Ocul Pharmacol Ther 199814 99-107.

43. Lema I, Brea D, Rodríguez-González R, Díez-Feijoo E, Sobrino T. Proteomic analysis of the tear film in patients with keratoconus, Mol Vis 201016 2055-2061.

44. Farris RL., Tear analysis in contact lens wearers. Trans Am Ophthalmol Soc 198583 501-545.

45. Ohashi Y, Dogru M, Tsubota K. Laboratory findings in tear fluid analysis. Clin Chim Acta 2006369 17-28.

46. Barniak VL, Burke SE, Venkatesh S. Comparative evaluation of multi-purpose solutions in the stabilization of tear lysozyme. Cont Lens Anterior Eye 201033 7-11.

47. Mann AM, Tighe BJ. Tear analysis and lens-tear interactions Part I. Protein fingerprinting with microfluidic technology. Cont Lens Anterior Eye 200730 163-173.

48. Gorskova EN, Tarasova LN, Teplova SN, Sevost'ianov EN, Alekhina TV. State of local immunity in keratoconus. Vestn Oftalmol 1998114 26-28.

49. Gasymov OK, Abduragimov AR, Yusifov TN, Glasgow BJ. Interaction of tear lipocalin with lysozyme and lactoferrin. Biochem Biophys Res Commun 1999265 322-325.

50. Glasgow BJ, Abduragimov AR, Farahbakhsh ZT, Faull KF, Hubbell WL, Tear lipocalins bind a broad array of lipid ligands. Curr Eye Res 199514 363-372.

51. Schoenwald RD, Vidvauns S, Wurster DE, Barfknecht CF. The role of tear proteins in tear film stability in the dry eye patient and in the rabbit. Adv Exp Med Biol 1998438 39-400.

52. Dartt DA. Neural regulation of lacrimal gland secretory processes: Relevance in dry eye diseases. Prog Retin Eye Res 200928 155-177.

53. Sorensen GL, Holmskov SHU. Surfactant protein A and surfactant protein $\mathrm{D}$ variation in pulmonary disease. Immunobiology 2007212 381-416.

54. Narayanan S, Miller WL, McDermott AM. Expression of human beta-defensins in conjunctival epithelium: relevance to dry eye disease. Invest Ophthalmol Vis Sci 2003 44 3795-3801.

55. Redfern RL, Reins RY, McDermott AM. Toll-like receptor activation modulates antimicrobial peptide expression by ocular surface cells. Exp Eye Res 201192 209-220.

56. Baveye S, Elass E, Mazurier J, Spik G, Legrand D. Lactoferrin: a multifunctional glycoprotein involved in the modulation of the inflammatory process. Clin Chem Lab Med 199937 281-286.

57. Jun AS, Cope L, Speck C, Feng X, Lee S, Meng H, Hamad A, Chakravarti S. Subnormal Cytokine Profile in the Tear Fluid of Keratoconus Patients. PLoS One 20116 e16437.

58. Lema I, Duran JA. Inflammatory molecules in the tears of patients with keratoconus. Ophthalmol 2005112 654-659.

59. Lynch MI, Cordeiro F, Ferreira S, Ximenes R, Oréfice F, Malagueño E. Lacrimal secretory $\operatorname{IgA}$ in active posterior uveitis induced by Toxoplasma gondii. Mem Inst Oswaldo Cruz 200499 861-864.

60. Glasson MJ, Stapleton F, Keay L, Willcox MDP. The effect of short term contact lens wear on the tear film and ocular surface characteristics of tolerant and intolerant wearers. Cont Lens Anterior Eye 200629 41-47.

61. Hoshino M, Shoji J, Inada N, Sawa M, Kato H. Clinical evaluation of a measurement method for secretory IgA in tears. Nippon Ganka Gakkai Zasshi 2006110 276-281.

62. Enríquez-de-Salamanca A, Castellanos E, Stern ME, 
Fernández I, Carreño E, García-Vázquez C, Herreras JM, Calonge M. Tear cytokine and chemokine analysis and clinical correlations in evaporative-type dry eye disease. $\mathrm{Mol}$ Vis 201016 862-873.

63. Massingale ML, Li X, Vallabhajosyula M, Chen D, Wei Y, Asbell PA. Analysis of inflammatory cytokines in the tears of dry eye patients. Cornea 200928 1023-1027.

64. Lam H, Bleiden L, de Paiva CS, Farley W, Stern ME, Pflugfelder SC. Tear cytokine profiles in dysfunctional tear syndrome. Am J Ophthalmol 2009 147 198-205.

65. Yoon KC, Jeong IY, Park YG, Yang SY. Interleukin-6 and tumor necrosis factor-alpha levels in tears of patients with dry eye syndrome. Cornea 200726 431-437.

66. Lema I, Sobrino T, Duran JA, Brea D, Diez-Feijoo E. Subclinical keratoconus and inflammatory molecules from tears. Br J Ophthalmol 200993 820-824.

67. Lema I, Duran JA, Ruiz C, Diez-Feijo E, Acera A, Merayo J.Inflammatory response to contact lenses in patients with keratoconus compared with myopic subjects. Cornea 2008 27 758-763.

68. Zywalewska-Górna N, Mrugacz M, Bakunowicz-Lazarczyk, A. The evaluation of chosen cytokines in induction of ocular changes in Sjögren's syndrome of dry eye. Klin Oczna 2007109 435-437.

69. Yoon KC, Park CS, You IC, Choi HJ, Lee KH, Im SK, Park HY, Pflugfelder SC. Expression of CXCL9, -10, -11, and CXCR3 in the tear film and ocular surface of patients with dry eye syndrome. Invest Ophthalmol Vis Sci 201051 643650 .

70. Malesiński R, Bakunowicz-Łazarczyk A, Wysocka J. The role of chemokines CCL3/ MIP-1 alfa and CCL4/ MIP-1 beta in pathogenesis of dry eye syndrome. Klin Oczna 2008 110 277-279.

71. Pannebaker C, Chandler HL, Nichols JJ. Tear proteomics in keratoconus. Mol Vis 201016 1949-1957.

72. Chotikavanich S, de Paiva CS, Li de Q, Chen JJ, Bian F, Farley WJ, Pflugfelder SC. Production and activity of ma- 